Огляди літератури, оригінальні дослідження, погляд на проблему, випадок з практики, короткі повідомлення УДК 616. $24-007.272-072: 661.5$

DOI 10.11603/1811-2471.2020.v.i3.11588

\title{
ВЗАИМОСВЯЗЬ АНАМНЕСТИЧЕСКИХ ПАРАМЕТРОВ, КЛИНИЧЕСКИХ ПРОЯВЛЕНИЙ И ФОРМИРОВАНИЯ ДИСФУНКЦИИ СОСУДИСТОГО ЭНДОТЕЛИЯ У БОЛЬНЫХ ХРОНИЧЕСКИМ ОБСТРУКТИВНЫМ ЗАБОЛЕВАНИЕМ ЛЕГКИХ
}

\section{ГУ «Днепропетровская медицинская академия МОз Украины»}

○Н. А. Ефимова

РЕЗЮМЕ. В настоящее время хроническое обструктивное заболевание легких (ХОЗЛ) рассматривается как системная патология. Среди внелёгочных проявлений выделяют кардиоваскулярные нарушения, наиболее ранним проявлением которых является эндотелиальная дисфункция. Однако в литературе отмечена неоднозначность данных, доказывающих влияние анамнестических, клинических параметров ХОЗЛ на формирование и прогрессирование эндотелиальной дисфункции.

Цель - изучение взаимосвязи между концентрацией NO в выдыхаемом воздухе у больных ХОЗЛ и некоторыми клинико-анамнестическими параметрами их заболевания в зависимости от стадии и фазы патологического процесса.

Материал и методы. Обследовано 25 мужчин, больных ХОЗЛ I-IV стадий, в ремиссии и обострении. В групу контроля вошли 11 практически здоровых лиц.

Результаты. Установлена корреляционная связь между концентрацией NO в выдыхаемом воздухе и длительностью заболевания ( $r=-0,67, \mathrm{p}=0,02)$ у больных ХОЗЛ III-IV стадий при обострении, что может свидетельствовать о формировании и прогрессировании эндотелиальной дисфункции с увеличением стажа заболевания. При этом в фазе ремиссии у данного контингента концентрация NO в выдыхаемом воздухе не зависела от исследуемого параметра. У больных ХОЗЛ, независимо от стадии и фазы патологического процесса, возраст, частота обострений в году, показатели функции внешнего дыхания не влияют на концентрацию N в выдыхаемом воздухе и, соответственно, не являются существенными параметрами, определяющими уровень исследуемого маркера у представленного контингента.

КЛЮЧЕВЫЕ СЛОВА: ХОЗЛ; эндотелиальная дисфункция; оксид азота в выдыхаемом воздухе.

Вступление. В настоящее время хроническое обструктивное заболевание легких (ХОЗЛ) рассматривается как системная патология, характеризующаяся различными внелёгочными проявлениями $[2,5]$, среди которых особого внимания заслуживают кардиоваскулярные нарушения, наиболее ранним проявлением которых является эндотелиальная дисфункция $(Э Д)[3,5]$.

Известно, что сосудистый эндотелий представлен высокоспециализированным метаболически активным монослоем клеток, способных к выработке вазорелаксирующих (оксид азота (NO), простациклин, эндотелиальный фактор гиперполяризации и др.) и вазоконстрикторных (эндотелин-1, тромбоксан А2 и др.) веществ, между которыми в физиологических условиях поддерживается равновесие. Доказано, что в патогенезе ЭД важнейшим фактором является NO. Рецепторы, находящиеся в эндотелии, преобразуя механические сигналы, индуцируют NO-синтазу, что приводит к накоплению NO и вазодилатации за счет снижения концентрации Са ${ }^{2+}$ в цитоплазме [1, $2,4]$. В связи с этим, большое число исследований у пациентов ХОЗЛ в настоящее время посвящено изучению состояния сосудистого эндотелия и развитию ЭД $[1,3]$. В литературе отмечена неоднозначность данных, доказывающих влияние анамнестических параметров и клинических проявлений ХОЗЛ на формирование, а также прогресси- рование ЭД, что и определило цель нашего исследования - изучение взаимосвязи между концентрацией NO в выдыхаемом воздухе у больных ХОЗЛ и некоторыми данными анамнеза, а также клиническими параметрами заболевания, в зависимости от стадии и фазы патологического процесса.

Материал и методы исследования. Обследовано 25 мужчин (средний возраст - $(61,13 \pm$ $2,10)$ лет, средняя длительность заболевания $(11,97 \pm 0,63)$ лет), болеющих ХОЗЛ I-IV стадий. Все они либо никогда не курили, либо воздерживались от курения более пяти лет. Диагноз был установлен в соответствии с критериями GOLD 2020 года и приказом МО3№555 от 27.06.2013 года. Все пациенты принимали стандартную терапию в зависимости от стадии заболевания.

Критерием исключения была сопутствующая патология сердечно-сосудистой системы (по данным анамнеза, объективного исследования, измерения АД, ЭКГ, ЭхоКГ и показателей липидного спектра крови).

Пациенты были поделены на 2 группы в зависимости от стадии заболевания: группу 1 составили 13 больных ХОЗЛ І-ІІ стадий, группу 2 12 больных ХОЗЛ III-IV стадий. Все исследования проводились дважды - в стадии обострения и ремиссии ХОЗЛ. В контрольную группу 3 было включено 11 практически здоровых добровольцев, ни- 
Огляди літератури, оригінальні дослідження, поглядн н когда не куривших, с нормальными показателями функции внешнего дыхания (ФВД).

Для верификации диагноза ХОЗЛ определяли показатели ФВД спомощью спирографа MasterLab (Jaeger, Германия): анализировали уровни объема форсированного выдоха за первую секунду $\left(\mathrm{OФ} \mathrm{B}_{1}\right)$, форсированной жизненной емкости легких (ФЖЕЛ), соотношения ОФВ $/$ ФЖЕЛ $;$; проводился тест на обратимость бронхиальной обструкции с $\beta_{2}$-агонистом короткого действия (сальбутамол 400 мкг). Также в ходе данного исследования оценивали концентрацию NO в выдыхаемом воздухе при помощи аппарата Niox Mino (Aerocrine). Измерение показателей ФВД и концентрации NO в выдыхаемом воздухе проводили с 8 до 10 утра натощак до приема лекарственных препаратов.

Для статистической обработки результатов использовалась программа «Statistica 7» с определением средней арифметической, критерия роблему, випадок з практики, короткі повідомлення достоверности различий и корреляционного анализа.

Результаты и обсуждение. Характеристика всех обследованных пациентов по параметрам возраста, стадии и длительности заболевания, а также числа обострений ХОЗЛ в году представлена в таблице 1, согласно данным которой пациенты всех групп были сопоставимы по возрасту, что свидетельствует о репрезентативности и сопоставимости данной выборки.

Во 2-й группе показатели длительности заболевания и количества обострений в году (табл. 1) были достоверно выше, что объясняется более тяжелым течением ХОЗЛ у данного контингента больных.

Показатели ФВД в группах, в зависимости от фазы заболевания и в сравнении с группой контроля (здоровые люди), представлены в таблице 2.

Таблица 1. Характеристика обследованных пациентов

\begin{tabular}{|c|c|c|c|}
\hline \multirow{2}{*}{ Показатели } & \multicolumn{3}{|c|}{ Группы } \\
\hline & $1(n=13)$ & $2(n=12)$ & $3(n=11)$ \\
\hline Стадия заболевания & I-II & III-IV & $\begin{array}{c}\text { Практически } \\
\text { здоровые }\end{array}$ \\
\hline 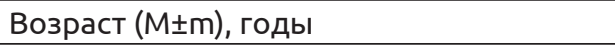 & $59,05 \pm 1,82$ & $63,20 \pm 2,38$ & $57,72 \pm 2,87$ \\
\hline 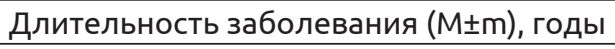 & $8,11 \pm 0,49$ & $15,83 \pm 0,76^{*}$ & - \\
\hline 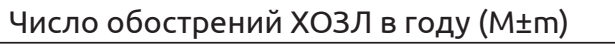 & $1,02 \pm 0,18$ & $2,11 \pm 0,26 *$ & - \\
\hline
\end{tabular}

Примечание. * $\mathrm{p}<0,05$ для показателей в 1 и 2 группах.

Таблица 2. Показатели функции внешнего дыхания в группах в зависимости от фазы заболевания

\begin{tabular}{|c|c|c|c|c|c|}
\hline \multirow{3}{*}{ Показатели } & \multicolumn{5}{|c|}{ Группы } \\
\hline & \multicolumn{2}{|c|}{$1(n=13)$} & \multicolumn{2}{|c|}{$2(n=12)$} & $3(n=11)$ \\
\hline & ремиссия & обострение & ремиссия & обострение & контроль \\
\hline 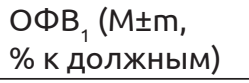 & $78,32 \pm 3,67$ & $67,95 \pm 3,01 *$ & $41,22 \pm 2,38$ & $37,25 \pm 2,51$ & $98,32 \pm 4,21$ \\
\hline 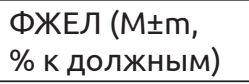 & $98,02 \pm 3,81$ & $86,70 \pm 3,50 *$ & $69,68 \pm 2,49$ & $68,72 \pm 3,85$ & $111,83 \pm 3,98$ \\
\hline ОФВ 1 /ФЖЕЛ & $68,56 \pm 2,1$ & $61,65 \pm 1,78^{*}$ & $44,68 \pm 2,25$ & $40,67 \pm 2,72$ & $89,52 \pm 1,46$ \\
\hline
\end{tabular}

Примечание. *p<0,05 для показателей в 1 группе.

Согласно полученным данным, уровни ОФВ $(p=0,037)$, ФЖЕЛ ( $p=0,039)$ и коэффициента ОФВ 1 ФЖЕЛ $(p=0,015)$ достоверно снижались при обострении только в группе 1, что может свидетельствовать о значимом нарушении ФВД у этих пациентов. По данным, приведенным в таблице 2, показатели ФВДбыли значительно ниже упациентов второй группы наблюдения с ХОЗЛ, что объясняется более высоким классом тяжести течения основного заболевания (ХОЗЛ III-IV стадий). Следует также отметить, что у практически здоровых лиц все показатели ФВД были достоверно выше (в 1,2-2,7 раза), чем у пациентов с ХОЗЛ, независимо от стадии или периода заболевания - ремиссия или обострение $(p<0,05)$. Проведение корреляционного анализа результатов обследования у пациентов с ХОЗЛ позволило выявить во 2-й группе (ХОЗЛ III-IV стадий) в периоде обострений (рис. 1) достоверную отрицательную корреляционную связь ( $r=-0,67, p=0,02)$ между концентрацией NO в выдыхаемом воздухе и длительностью заболевания. При этом у представленного контингента в период ремиссии между исследуемыми параметрами установить связь не удалось $(r=0,12, p=0,71)$.

Наиболее вероятно, у больных при тяжелом течении ХОЗЛ в обострении со стажем заболевания снижается продукция NO, что может служить ранним признаком формирования и прогресси- 
Огляди літератури, оригінальні дослідження, погляд на проблему, випадок з практики, короткі повідомлення

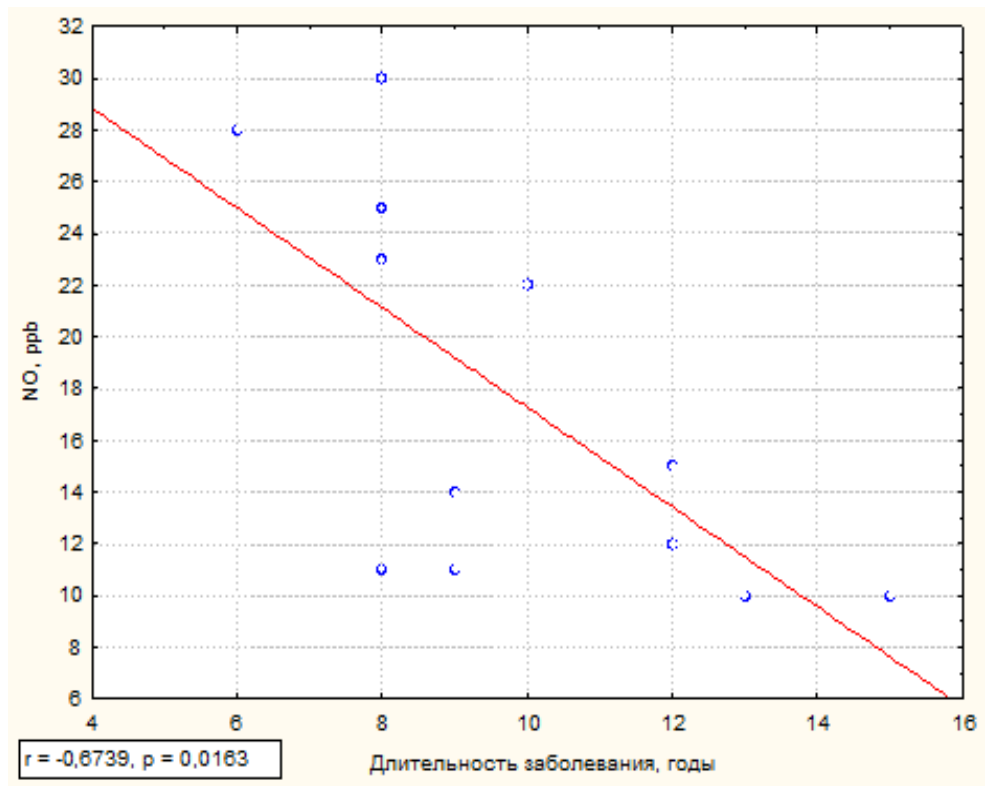

Рис. 1. Взаимосвязь уровня выдыхаемого O и длительности заболевания в группе 2 при обострении.

рования ЭД, а также оказывать негативное влияние на прогноз заболевания. При этом у пациентов в ремиссии при тяжелом течении ХОЗЛ уровень NO не зависел от длительности заболевания, что, возможно, свидетельствует о стабильном течении дисфункции сосудистого эндотелия вне периода обострения.

У больных с нетяжелым течением заболевания, независимо от фазы патологического процесса, достоверная корреляционная связь между уровнем NO и длительностью заболевания не зарегистрирована (в ремиссии - $r=-0,15, p=0,63$, в обострении - $r=0,47, p=0,10)$, что может подтверждать менее существенную зависимость между уровнем исследуемого маркера ЭД и длительностью заболевания у представленного контингента больных.

Также не было зарегистрировано достоверной корреляционной взаимосвязи между уровнем NO в выдыхаемом воздухе и возрастом пациентов в группе 1 (в ремиссии - $r=0,23, p=0,47$, в обострении - $r=0,14, p=0,28)$ и в группе 2 (в ремиссии $r=-0,11, p=0,37$, в обострении $-r=0,20, p=0,25)$.

Таким образом, возраст пациентов, независимо от стадии и фазы патологического процесса, в исследуемых группах не являлся значимым предиктором, влияющим на уровень NO в выдыхаемом воздухе. Наиболее вероятно, для изучения влияния возраста пациентов на состояние сосудистого эндотелия необходимо исследование уровня NO в выдыхаемом воздухе в сочетании с другими маркерами ЭД.

Кроме того, была зафиксирована недостоверная корреляционная взаимосвязь между уровнем NO в выдыхаемом воздухе и частотой обострений
ХОЗЛ в году, как в группе 1 (в ремиссии - r=-0,06, $p=0,84$, в обострении $-r=-0,17, p=0,57)$, так и в группе 2 (в ремиссии - $r=-0,16, p=0,61$, в обострении $r=0,23, p=0,47)$. Также не выявлена зависимость между основными показателями, характеризующими ФВД, и уровнем NO в выдыхаемом воздухе. Так, корреляционная связь с показателем ОФВ 1 в группе 1 составила $r=-0,18, p=0,57$ в ремиссии и $r=-0,21, p=0,48$ в обострении; в группе $2-r=0,28$, $\mathrm{p}=0,53$ в ремиссии и $r=0,19, \mathrm{p}=0,35$ в обострении.

Таким образом, независимо от стадии и фазы ХОЗЛ, число обострений заболевания в году и показатели ФВД не ассоциируются с изменением уровня NO в выдыхаемом воздухе у исследуемой когорты пациентов, являясь, наиболее вероятно, менее значимыми маркерами, свидетельствующими о прогрессировании ЭД.

Выводы. 1. У некурящих больных ХОЗЛ III-V стадий при обострении с увеличением длительности заболевания концентрация NO в выдыхаемом воздухе снижается, что, наиболее вероятно, может свидетельствовать о формировании и прогрессировании эндотелиальной дисфункции.

2. У некурящих больных ХОЗЛ III-IV стадий в фазе ремиссии концентрация NO в выдыхаемом воздухе не зависит от длительности заболевания, что может быть ассоциировано со стабильным состоянием сосудистого эндотелия.

3. У некурящих больных ХОЗЛ, независимо от стадии и фазы патологического процесса, возраст, частота обострений в году, показатели функции внешнего дыхания не влияют на концентрацию NO в выдыхаемом воздухе и, соответственно, не являются существенными параметрами, влияющими на уровень исследуемого маркера. 
Огляди літератури, оригінальні дослідження, погляд на проблему, випадок з практики, короткі повідомлення

Перспективы дальнейших исследований. При дальнейшем исследования влияния анамнестических и клинических параметров ХОЗЛ на развитие и формирование ЭД целесообразно учитывать уровень NO в выдыхаемом воздухе в сочетании с лабораторными (эндотелин-1, альвеолярные макрофаги и др.) и инструментальными (окклюзионная проба, проба с нитроглицерином) показателями дисфункции сосудистого эндотелия.

\section{ЛИТЕРАТУРА}

1. Влияние курения на концентрацию оксида азота в выдыхаемом воздухе у пациентов с хроническим обструктивным заболеванием легких / Т. А. Перцева, Е. Ю. Гашинова, Н. А. Ефимова // Украинский пульмонологический журнал. - 2010. - № 3. - С. 66-68.

2. Клиническое значение изменений метаболизма оксида азота в пульмонологии / Т. В. Звягина, Т. В. Аникеева, Т. М. Белоконь // Украинский пульмонологический журнал. - 2012. - № 1. - С. 66-68.

3. Показатели функции эндотелия и функциональное состояние респираторной системы при различной степени тяжести вентиляционных нарушений у больных ХОЗЛ / В. В. Ефимов, В. И. Блажко, Л. С. Воейкова [и др.] // Український терапевтичний журнал. - 2011. № 3. - С. 44-47.

4. Роль оксида азота в патофизиологии и лечении хронической обструктивной болезни легких / О. Ю. Кытикова, Т. А. Гвозденко, М.В.Антонюк [и др.] // Бюллетень физиологии и патологии дыхания. - 2019.- № 71 C. 105-111. - Режим доступа: https://riorpub.com/ru/ nauka/article/27894/view

5. Global Initiative for Chronic Obstructive Lung Diseases (GOLD). Global strategy for diagnosis, management, and prevention of chronic obstructive pulmonary disease. Access mode : https:/goldcopd.org/wp-content/uploads/ 2019/11/GOLD-2020-REPORT-ver1.0wms.pdf

\title{
REFERENCES
}

1. Pertseva, T.A., Gashinova, E.Yu., \& Efimova, N.A. (2010). Vliyanie kureniya na kontsentratsiyu oksida azota $v$ vyidyihaemom vozduhe u patsientov s hronicheskim obstruktivnyim zabolevaniem legkih [The effect of smoking on the concentration of nitric oxide in exhaled air in patients with chronic obstructive pulmonary disease]. Ukrainskiy pulmonologicheskiy zhurnal - Ukrainian Pulmonological Journal, 3, 66-68 [in Russian].

2. Zvyagina, T.V., Anikeeva, T.V., \& Belokon, T.M. (2012). Klinicheskoe znachenie izmeneniy metabolizma oksida azota $v$ pulmonologii [The clinical significance of changes in nitric oxide metabolism in pulmonology]. Ukrainskiy pulmonologicheskiy zhurnal - Ukrainian Pulmonological Journal, 1, 66-68 [in Russian].

3. Efimov, V.V., Blazhko, V.I., \& Voeykova, L.S. (2011). Pokazateli funktsii endoteliya i funktsionalnoe sostoyanie respiratornoy sistemy pri razlichnoy stepeni tyazhesti ven-

tilyatsionnykh narusheniy u bolnykh HOZL [Indicators of endothelial function and the functional state of the respiratory system with varying degrees of severity of ventilation disorders in patients with COPD]. Ukrainskyi terapevtychnyi zhurnal - Ukrainian Therapeutic Journal, 3, 44-47 [in Russian].

4. Kyitikova, O.Yu., Gvozdenko, T.A., \& Antonyuk, M.V. (2019). Rol oksida azota v patofiziologii i lechenii khronicheskiy obstruktivnoy bolezni legkih [The role of nitric oxide in the pathophysiology and treatment of chronic obstructive pulmonary disease]. Byulleten fiziologii i patologii dykhaniya-Respiratory Physiology and Pathology Bulletin, 71, 105-111. Retrieved from: https://riorpub.com/ru/nauka/article/27894/view.

5. Global Initiative for Chronic Obstructive Lung Diseases (GOLD). Global strategy for diagnosis, management, and prevention of chronic obstructive pulmonary disease. Retrieved from: https:/goldcopd.org/wp-content/uploads/ 2019/11/GOLD-2020-REPORT-ver1.0wms.pdf.

\section{ВЗАЕМОЗВ'ЯЗОК АНАМНЕСТИЧНИХ ПАРАМЕТРІВ, КЛІНІЧНИХ ПРОЯВІВ I ФОРМУВАННЯ ДИСФУНКЦІї СУДИННОГО ЕНДОТЕЛІЮ У ХВОРИХ НА ХРОНІЧНЕ ОБСТРУКТИВНЕ ЗАХВОРЮВАННЯ ЛЕГЕНЬ}

\author{
๑Н. О. Єфімова
}

\author{
ДУ «Дніпропетровська медична академія МОЗ України»
}

РЕзюМЕ. На сьогодні хронічне обструктивне захворювання легень (ХОЗЛ) розглядається як системна патологія. Серед позалегеневих проявів виділяють кардіоваскулярні порушення, найбільш ранніми проявами яких $\epsilon$ ендотеліальна дисфункція. Однак в літературі відзначена неоднозначність даних, які доводять вплив анамнестичних, клінічних параметрів ХОЗЛ на формування і прогресування ендотеліальної дисфункції.

Мета - вивчення взаємозв'язку між концентрацією NO в повітрі, що видихається, у хворих на ХОзЛ і деякими клініко-анамнестичними параметрами їх захворювання залежно від стадії та фази патологічного процесу.

Матеріал і методи. Обстежено 25 чоловіків, хворих на ХОЗЛ I-IV стадій, в ремісії та загостренні. В групу контролю увійшли 11 практично здорових осіб. 
Огляди літератури, оригінальні дослідження, погляд на проблему, випадок з практики, короткі повідомлення

Результати. Встановлено кореляційний зв'язок між концентрацією N в повітрі, що видихається, і тривалістю захворювання ( $r=-0,67, p=0,02)$ у хворих на XО3Л III-IV стадій при загостренні, що може свідчити про формування та прогресування ендотеліальної дисфункції зі збільшенням терміну захворювання. При цьому в фазі ремісії у вказаного контингенту концентрація NO в повітрі, що видихається, не залежала від досліджуваного параметра. У хворих на ХОЗЛ, незалежно від стадії і фази патологічного процесу, вік, частота загострень на рік, показники функції зовнішнього дихання не впливають на концентрацію NO в повітрі, що видихається і, відповідно, не $\epsilon$ істотними параметрами, що визначають рівень досліджуваного маркера у представленого контингенту.

КЛючОВІ СЛОВА: ХОЗЛ; ендотеліальна дисфункція; оксид азоту у повітрі, що видихається.

\section{INTERRELATION OF ANAMNESTIC PARAMETERS, CLINICAL MANIFESTATIONS AND FORMATION OF VASCULAR ENDOTHELIAL DYSFUNCTION IN PATIENTS WITH COPD}

๑N. A. Efimova

\section{Dnipropetrovsk Medical Academy}

SUMMARY. Currently, COPD is considered a systemic pathology. Among the extrapulmonary manifestations, cardiovascular disorders are distinguished, the earliest manifestations of which are endothelial dysfunction. However, the literature has noted the ambiguity of data proving the effect of anamnestic, clinical parameters of COPD on the formation and progression of endothelial dysfunction.

The aim was to study the relationship between the concentration of NO in the exhaled air in patients with COPD and some clinical and anamnestic parameters of their disease, depending on the stage and phase of the pathological process.

Material and Methods. We examined 25 male patients with COPD stage I-IV in remission and exacerbation, the control group included 11 healthy people.

Results. A correlation was established between the concentration of NO in the exhaled air and the duration of the disease $(r=-0.67, p=0.02)$ in patients with stage III-IV COPD during exacerbation, which may indicate the formation and progression of endothelial dysfunction with an increase in the length of the disease. At the same time, in the phase of remission in this contingent, the concentration of NO in the exhaled air did not depend on the studied parameter. In patients with COPD, regardless of the stage and phase of the pathological process, age, frequency of exacerbations per year, indicators of the function of external respiration do not affect the concentration of NO in exhaled air and, accordingly, are not essential parameters that determine the level of the studied marker in the presented contingent.

KEY WORDS: COPD; endothelial dysfunction; nitric oxide in exhaled air.

Отримано 14.08.2020 